ARTIGO

Recebido em:

28/04/2017

Aceito em: 09/04/2018

\title{
Empresa júnior na atuação do profissional consultor de Biblioteconomia: um estudo de caso a partir da Universidade Federal de Goiás
}

\author{
Junior company in the work of the professional consultant of \\ Librarianship: a case study from the Federal University of Goiás
}

Thayse MENDES $(\underline{\text { thaybiblio@gmail.com })}$
Paulo FRAGA $(\underline{\text { paulo.s.fraga } @ g m a i l . c o m})^{*}$
Ilaydiany OLIVEIRA $(\underline{\text { ilaydiany18@ } 18 \text { hotmail.com }})^{* *}$
${ }^{*}$ Graduando do Curso de Biblioteconomia da Universidade Federal de Goiás.
$* *$ Professora do Curso de Biblioteconomia da Universidade Federal de Goiás.

\section{Resumo}

Objetiva identificar se os alunos do Curso de Biblioteconomia da Universidade Federal de Goiás possuem um perfil consultor proporcionado pelos recursos oferecidos através da Empresa júnior do Curso. 0 estudo é permeado pela problematização de verificar se a Empresa júnior tem contribuído na formação profissional dos futuros bibliotecários do estado de Goiás. Para tanto, busca identificar os principais marcos históricos que contam a história da Empresa júnior de biblioteconomia da Universidade Federal de Goiás, analisa as pretensões dos graduandos de biblioteconomia em trabalhar na linha empresarial e a influência da Empresa júnior na atuação de consultoria. Utiliza um procedimento bibliográfico para fundamentar as ideias apresentadas e com o pressuposto de compreender mais detalhadamente o assunto, delimita-se um estudo de caso com uma abordagem quantitativa e qualitativa através do método descritivoexplicativo de dados coletados por meio do procedimento de aplicação de questionários e entrevista com professores e alunos. Conclui-se que os alunos do Curso de Biblioteconomia possuem entendimento sobre o que é uma Empresa júnior e como a mesma é capaz de ofertar conhecimentos acerca de atividades de consultoria para os futuros profissionais bibliotecários do estado de Goiás, assim como é constatado a vontade e interesse dos alunos em participar da Empresa júnior, bem como atuar na área de consultoria. Porém, identifica-se que a Empresa júnior existente não é ativa e não é capaz de oferecer subsídios intelectuais e profissionais aos alunos que possuem o interesse em fazer parte da mesma, devido à falta de divulgação em torno da empresa e a não realização de atividades devido ao encerramento de suas funções.

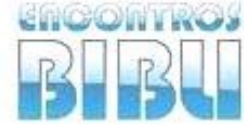

v. 23 , n. esp., 2018 p. $25-40$

ISSN 1518-2924
Palavras-chave: Competências Profissionais. Empreendedorismo. Consultor de Informação. Bibliotecário.

\section{Esta obra está licenciada sob uma Licença Creative Commons.}




\begin{abstract}
It aims to identify if the students of the Librarianship Course of the Federal University of Goiás have a consultant profile provided by the resources offered through the Junior Company of the course. The study has as its main questioning to verify if the Junior Company has contributed to the professional background of the future librarians of the state of Goiás. To do so,

seeks to identify the main landmarks that tell the story of the junior librarianship company of the Federal University of Goiás, it analyzes the intentions of undergraduate librarians to work in the business line and the influence of the Junior Company in the consulting practice. It utilizes a bibliographic procedure to underlie the ideas presented and with the presupposition to understand the issue in detail, a case study is delimited with a quantitative and qualitative approach through a descriptive-explanatory method of data collection by applying questionnaires and conducting interviews with professors and undergraduate students. It may be concluded that the students of the Librarianship course have an understanding of what a Junior Company is and how it is able to offer knowledge about consulting activities for future librarians in the state of Goiás, besides their willingness and interest in participating in the Junior Company, as well as acting in the consulting area. However, it is identified that the existing Junior Company is not active and is not able to offer intellectual and professional subsidies to students who have an interest in being part of it, due to the lack of disclosure of the company and to the non-performance of activities once its functions have terminated.
\end{abstract}

Keywords: Professional Competences. Entrepreneurship. Information Consultant. Librarian.

\title{
1 INTRODUÇÃO
}

A Empresa júnior trata-se de uma iniciativa de professores e estudantes em busca de adaptação e adequação dos alunos no mercado de trabalho, visto a possibilidade da prática vivenciada por meio da consultoria dos futuros profissionais.

Nesse âmbito, observa-se que o Curso de Biblioteconomia apresenta uma variedade de atuações dentro da sua formação, como: bibliotecas escolares, centros de documentação, arquivos, livrarias, editoras, empresas e consultorias. Através desse raciocínio, observa-se o surgimento de um perfil de bibliotecários autônomos e prestadores de serviços, que muitas vezes têm esse desejo despertado através de programas desenvolvidos na própria instituição de ensino superior em que se formam.

Observa-se que a faculdade é o primeiro contato do aluno com as possibilidades de atuação no mercado, já que através de projetos, aulas, trabalhos e oportunidades, o aluno tende a perceber o que mais se enquadra aos seus interesses e acaba por delimitar seu perfil ao que ele pode e deseja fazer. Sendo assim, quanto mais possibilidades a faculdade propor, a mente do discente ampliará para mais áreas de atuação.

Partindo desse pressuposto, verifica-se que a universidade exerce um papel importante para a formação e incentivo à criação do perfil consultor na área de biblioteconomia. E nesse âmbito, observa-se que o quadro do mercado de trabalho para o profissional bibliotecário vai além do que simplesmente a biblioteca, ele também pode atuar na implantação de uma unidade analisando as instalações para saber se é um lugar adequado para a conservação do acervo ali existente ou que irá existir, pode oferecer serviços de referência em busca de informações sobre assuntos específicos para pesquisadores, ofertar cursos de pesquisa (básica e avançada) em sites de forma a aumentar a precisão das buscas, entre outras atividades que podem oferecer como 
consultor.

O tema escolhido para este estudo circunda o entendimento do seguinte questionamento: diante da relevância da existência de Empresas juniores nos âmbitos universitários, é possível verificar se a Empresa júnior do Curso de Biblioteconomia da Universidade Federal de Goiás (UFG) tem contribuído na formação profissional dos futuros bibliotecários do estado de Goiás?

Por meio dessa inquietação, define-se por objetivo geral identificar se os alunos do Curso de Biblioteconomia da UFG possuem um perfil consultor proporcionado pelos recursos oferecidos através da Empresa júnior do Curso de Biblioteconomia. Por objetivos específicos busca-se: identificar os principais marcos históricos que contam a história da Empresa júnior de biblioteconomia da UFG, verificar se os alunos pretendem trabalhar como consultores; analisar se eles conhecem a Empresa júnior do curso; identificar se os mesmos participaram ou participam da criação ou funcionamento da Empresa júnior; constatar se os alunos acham que a empresa contribui para a formação do perfil consultor; e verificar se os graduandos do curso desejam atuar na área de consultoria.

Na perspectiva de atingir tais objetivos, delimita-se como objeto de estudo desta pesquisa os estudantes do Curso de Biblioteconomia da UFG e a Empresa júnior existente na mesma. Assim utiliza-se uma metodologia aplicada que tem abordagem tanto quantitativa quanto qualitativa, já que, segundo Gerhardt e Silveira (2009), a pesquisa qualitativa, assim como a do presente artigo, preocupa-se em explicar o porquê dos acontecimentos e fatos, buscando através da descrição compreender e explicar os fenômenos ocorridos; é considerada também quantitativa visto que há mensuração dos resultados. Conforme Fonseca (2002), uma pesquisa quantitativa usa da linguagem matemática para explicar os resultados, sendo que analisando destas duas maneiras podem-se recolher mais informações do que se poderia conseguir isoladamente.

Quanto ao objetivo define-se como descritiva e exploratória, pois segundo Gil (2007) quando descritiva narra fenômenos de uma determinada realidade e exploratória, por proporcionar uma familiaridade ao problema estudado tornando-o mais explícito. E utiliza a aplicação de questionários e entrevistas com discentes e docentes do Curso de Biblioteconomia da UFG buscando compreender os fatos históricos que circundam a criação da Empresa júnior, visto não existir documentos sobre a Empresa, bem como responder aos objetivos e problematizações deste estudo.

A presente pesquisa apresenta-se como documental, pois utiliza diversas fontes (estas nem sempre de tratamento analítico) se enquadra como um estudo de caso, pois pretende conhecer o como e o porquê de ocorrer determinada situação com a tentativa de descobrir o que há nela de mais característico (FONSECA, 2002).

Assim, foi feito uma investigação nas faculdades que possuem o Curso de Biblioteconomia para saber quais delas possuem ou já possuíram Empresa júnior, fazendo uma quantificação das mesmas e uma análise acerca da presença da Empresa júnior na formação dos futuros profissionais.

O tema foi escolhido a partir da observação sobre a importância da atuação de uma Empresa júnior para auxiliar os alunos de graduação a se incorporarem e conhecerem o mercado de trabalho. Dessa forma, almeja-se que a partir de uma maior divulgação científica acerca da contribuição da Empresa júnior para a capacitação profissional, diversas universidades adotem ou invistam mais nesse tipo de empresa, de modo a formar profissionais mais capacitados para atender a sociedade e suas necessidades atuais. 


\section{EMPRESA JÚNIOR NA BIBLIOTECONOMIA}

Segundo Matos (1997) a Empresa júnior é como uma instituição regida por um estatuto, sendo que não possui fins lucrativos, e é gerida por estudantes de graduação da faculdade em que está inserida, com o objetivo principal de proporcionar aos estudantes a aplicação dos conhecimentos teóricos adquiridos.

Da mesma forma, a Brasil Júnior (2007) ressalta que essas empresas são formadas pela união de alunos matriculados em uma instituição de ensino superior com o objetivo de realizar projetos e serviços que contribuam com o desenvolvimento do país, formando através desse trabalho, profissionais capacitados, além de desenvolver profissionalmente as pessoas que compõem o quadro social por meio da vivência empresarial e fomentar o empreendedorismo de seus associados.

Esse tipo de empresa é, conforme o Conceito Nacional de Empresa júnior - CNEJ (2007), formado pela junção de alunos matriculados em cursos de graduação em instituições de ensino superior e tem por objetivo realizar projetos ou serviços que contribuam para o desenvolvimento do país através da formação de profissionais capacitados.

Nesse tocante, a biblioteconomia por ter a informação como sua principal fonte de trabalho, possibilita por sua formação uma ampla variedade de atuações, já que a informação está contida em quase todos os espaços, sejam eles bibliotecas, empresas, ONGs e/ou universidades.

Observa-se que com a ascensão da internet e o aumento de informações desde a criação da imprensa, pode-se dizer que a área de atuação do bibliotecário se expande cada vez mais. Dessa forma, segundo a nova Classificação Brasileira de Ocupações - CBO (2002), esses profissionais:

Disponibilizam informação em qualquer suporte; gerenciam unidades como bibliotecas, centros de documentação, centros de informação e correlatos, além de redes e sistemas de informação. Tratam tecnicamente e desenvolvem recursos informacionais; disseminam informação com o objetivo de facilitar o acesso e geração do conhecimento; desenvolvem estudos e pesquisas; realizam difusão cultural; desenvolvem ações educativas; podem prestar serviços de assessoria e consultoria.

Porém, apesar da possibilidade de atuação prestando consultoria, esse tema ainda é pouco discutido no meio acadêmico apesar de haver demanda no mercado, pois a atuação dos bibliotecários no mercado informacional tradicional que "é composto por bibliotecas públicas, universitárias, especializadas, escolares, centros culturais e arquivos" (PINHEIRO et al., 2012, p. 3) ainda é enorme.

Ainda segundo Pinheiro et al. (2012) outras áreas de ocupação ainda permanecem com pouca atuação, seja por falta de informação, comodidade profissional, tradicionalismo, ou desconhecimento da população sobre essas diversas atuações, cabendo ainda ao profissional se redescobrir quanto a sua profissão e se capacitar para atuar na área pretendida.

A consultoria é uma atividade, conforme Milano e Davok (2009), que objetiva responder ou atender às necessidades do solicitante por meio de aconselhamento ou proposição, assim como os ramos da biblioteconomia que não são exercidas no mercado informacional tradicional, tem sua abrangência no mercado pouco marcada.

Nessa perspectiva, observa-se a necessidade de participação assídua de consultorias pelos profissionais da biblioteconomia, visto que se trata de uma área de atuação que precisa ser difundida entre estes profissionais como forma de abranger seu 
campo de atuação e delimitar um mercado de trabalho mais amplo.

Sendo assim, evidencia-se a necessidade cada vez mais intensa dos cursos de Biblioteconomia do Brasil em incentivar a atuação nessa área por meio de práticas como a implantação de Empresa júnior. Pois, mediante o contato dos alunos com a prática das atividades desempenhadas na Empresa júnior há a possibilidade dos mesmos terem familiaridade com a prática e assim despertar para esse mercado de trabalho.

0 contato do graduando diretamente com a área profissional possibilita que este possa ser preparado para situações possíveis e reais no mercado de trabalho. Dessa forma, os cursos devem se atentar para o fato de que o viés empreendedor que a Empresa júnior fornece ao aluno é benéfico e, portanto, deve ser incentivado.

A faculdade ao apresentar essa estrutura ao aluno possibilita que ele ponha em prática todo conhecimento adquirido nas aulas das mais diversas matérias, sejam elas sociais, culturais ou educacionais, já que dentro desse contexto ele terá a oportunidade de desenvolver projetos e consultorias que colaborem e ajudem a sociedade em geral.

\section{METODOLOGIA}

Buscando atingir o objetivo deste estudo, a metodologia foi dividida em três fases. Na fase 1 foi realizado um levantamento documental acerca da história do Curso de Biblioteconomia, bem como de sua Empresa júnior.

$\mathrm{Na}$ fase 2, aplicou-se entrevistas com as professoras do Curso, Laura Vilela Rodrigues, Maria de Fátima Garbeline e Geisa Muller de Campos Ribeiro que integraram a empresa, com a aluna Anna Gemma Loccatelli de Oliveira e o aluno Otacilio Carlos Borges da Silva, que também fizeram parte do projeto.

As entrevistas foram realizadas no âmbito da UFG nos dias 09 e 10 de março de 2017. Teve um total de 10 perguntas que buscavam coletar as informações importantes pertinentes à história e formação da Empresa júnior do curso e compreender lacunas existentes, visto que a fase 1 não foi tão bem-sucedida, devido à falta de documentos sobre a Empresa júnior. Todos os resultados foram analisados através do método descritivo-exploratório que utiliza como embasamento um levantamento bibliográfico sobre o assunto a partir de teóricos da área.

$\mathrm{Na}$ fase 3 foi empregue uma metodologia de abordagem quantitativa e qualitativa por meio da aplicação de um questionário fechado, através do Google Formulário, com os alunos do curso, o questionário continha 10 questões acerca do interesse dos discentes em participar da Empresa júnior existente no curso, bem como analisar o nível de conhecimento acerca das atividades desempenhadas pela empresa por parte dos alunos.

0 curso possui atualmente um total de 219 alunos, dentre estes, cerca de 170 são ativos e matriculados. Dessa forma, o questionário foi enviado, entre os dias 8 a 15 de março de 2017, para um total de 115 alunos de todos os períodos e teve um índice de respostas equivalente a 35 , ou seja, $30 \%$ dos alunos alvos desse estudo participaram da pesquisa.

\section{RESULTADOS: APRESENTAÇÃO E DISCUSSÃO}

Nesse capítulo serão apresentados os resultados encontrados, de princípio se apresenta uma breve história sobre a Empresa júnior, construída por meio de entrevistas com discentes e docentes e logo após apresenta-se os dados referentes a busca de interesse dos discentes quanto a atuação da Empresa júnior na UFG. 


\subsection{Uma breve história acerca da empresa júnior do curso de Biblioteconomia da Universidade Federal de Goiás}

Buscando identificar os principais marcos históricos que contam a história da Empresa júnior de biblioteconomia da Universidade Federal de Goiás, se faz necessário, inicialmente, falar sore o Curso de Biblioteconomia na UFG.

Segundo Souza (2017), foi criado em 22 de junho de 1979, pela resolução no 135, após a insistência da escritora e bibliotecária Marietta Telles Machado, que via a importância da criação do curso no estado de Goiás. Assim, o curso teve sua primeira turma em 1980 que contava com 20 vagas e era ligada ao Instituto de Ciências Humanas e Letras.

Inicialmente, segundo o terceiro artigo do decreto, as matérias dos cursos eram:

Art. $3^{\circ}$ - Ficam criadas para o Curso as seguintes disciplinas: Introdução à Biblioteconomia, História do Livro e das Bibliotecas, Planejamento e Estudo do Usuário I e II, Organização e Administração de Bibliotecas I, II e III, Catalogação, Classificação I e II, Bibliografia, Bibliografia Brasileira, Bibliografia Especializada I, II, III, IV, V, VI e VIII, Documentação I e II e Paleografia. (UNIVERSIDADE...1979)

Esse primeiro currículo prevaleceu de 1980 a 2004 e se baseou em uma formação generalista, na qual o profissional bibliotecário era apresentado a uma grade curricular pautada em uma perspectiva tecnicista ampla para que a adequasse ao seu desempenho profissional futuro.

Ainda segundo a autora, em 1996 é criada a Faculdade de Comunicação e Biblioteconomia (FACOMB) incorporando o Curso de Biblioteconomia (1980), Jornalismo (1968), Relações Públicas (1975) e Radialismo (1981). Anos depois, Publicidade e Propaganda (1997) e o Curso de Gestão da Informação (2012).

Em 2004, o currículo passa por transformações, buscando alterações propostas que pretendiam superar a condição tecnicista do modelo norte americano, caracterizado por um conjunto padrão de recursos instrumentais, de modo a constituir um novo parâmetro no qual os alunos escolhem a partir do quinto período se desejam seguir a vertente de ênfases de social e educacional ou empresarial. Esse modelo vigorou até 2016 e apresentou disciplinas que contribuíram para o envolvimento do aluno com as áreas de empreendedorismo, tais como administração, marketing em unidades de informação e administração de unidades de informação.

Após 2016, e com a mudança do currículo, a ênfase empresarial e educacional são extintas, delimitando-se então uma única ênfase, educacional, social e cultural, mediante a criação do curso de Gestão da Informação na UFG, o qual aborda com maior especificidade uma atuação voltada para informação científica, tecnológica e industrial; e adequação ao Plano Nacional de Educação (lei no13.005 de 25 de 2014) e ao Plano Nacional de Cultura (lei no12.343 de 2 de Dezembro de 2010) (PROJETO POLÍTICO PEDAGÓGICO, 2016), não sabendo assim quais os impactos gerados para o envolvimento com o empreendedorismo por parte dos alunos.

Porém, os mesmos têm a oportunidade de entrar em contato com a atuação empreendedora dentro da Universidade Federal de Goiás, já que ela através do Centro de Empreendedorismo e Incubação (CEI) promove projetos como o UFG Empreende há três anos, onde qualquer pessoa que tenha vínculo com a UFG pode participar (CENTRO DE EMPREENDEDORISMO E INCUBAÇÃO, 2017).

O CEI promove palestras para incentivar o empreendedorismo. Uma das suas preocupações é orientar sobre o processo de abertura da Empresa júnior, que deve 
seguir os seguintes passos:

1. Ampla divulgação da futura empresa;

2. Redigir o Estatuto Social;

3. Realizar a Assembléia Geral de Fundação, Eleição e Posse da Diretoria e aprovação do estatuto;

4. Levar os documentos ao Cartório de Registro de Pessoas Jurídicas;

5. Levar os seguintes documentos à PRPI; e

6. Providenciar os registros de CNPJ; fazer a inscrição municipal; obter o Conceito Nacional de Empresa júnior (CNEJ), documento emitido pela Brasil Júnior.

Nesse âmbito, mediante o apoio oferecido pela UFG, em meados de 2013 o Curso de Biblioteconomia promoveu à proposta de implantar a Empresa júnior no curso e envolver os alunos de ambas as ênfases, visto que as atividades propostas a serem exercidas favoreciam ambas, não só a empresarial.

De acordo com entrevista concedida pelas Professoras Laura Vilela Rodrigues, Maria de Fátima Garbeline e Geisa Muller de Campos Ribeiro relatou-se que alguns alunos do Curso de Biblioteconomia reuniram-se com o apoio das professoras e encabeçaram o projeto de criar a Empresa júnior do curso, visto o interesse dos estudantes.

Durante as entrevistas verificou-se que a Empresa júnior do Curso de Biblioteconomia da UFG apesar de ter sido criada em 2013, ficou atuando sem estar formalizada legalmente, ou seja, atuou sem apresentar à instituição as documentações necessárias para a seu registro.

A partir dos dados coletados pôde-se observar que a Empresa júnior do Curso de Biblioteconomia da UFG não funcionou de forma regularizada, pois por meio da entrevista realizada com a Professora Laura Vilela Rodrigues Rezende, responsável pela administração da empresa, foi informado que "a empresa exerceu atividades informalmente, pois a mesma não deu entrada na documentação necessária para a sua ativação, mas, havia interesse dos professores em regularizá-la".

Por um curto tempo ocupou uma sala no Laboratório de Informação e Comunicação (LABICOM), localizado no Campus Samambaia da UFG. Dentre os serviços que eram oferecidos estavam: formatação de trabalhos, pesquisa bibliográficas, sendo que o diferencial seria a criação de projetos em relação à biblioteca e cultura.

Durante as entrevistas, relatou-se que a aluna Anna Gemma Loccatelli de Oliveira foi a primeira presidente e representante da Empresa júnior e contou com o auxílio do aluno Otacilio Carlos Borges da Silva, que assumiu a gestão da Empresa júnior do curso em momento posterior, além de mais três alunos, que não foram identificados. Ao entrevistar o aluno e aluna, eles informaram que a experiência em atuar com consultoria foi muito enriquecedora e que despertou neles uma visão empreendedora para a área de consultoria, porém eles alegaram que se desligaram da Empresa, visto que não havia remuneração financeira para atuação na mesma e por isso eles procuraram um estágio remunerado para atuarem, e, assim, abriram mão da empresa, que logo após veio a deixar de existir.

Em meados de 2015 a Empresa passou por um período em que funcionou com a supervisão da professora Maria de Fátima Garbelini. Nesse mesmo período foi organizado uma oficina de empreendedorismo que tinha por objetivo incentivar o lado empreendedor de cada aluno no curso mostrando como o profissional bibliotecário pode atuar dentro do mercado de trabalho em ambientes não convencionais de trabalho do mesmo, assim como empreender dentro dos ambientes convencionais.

Ressalta-se que durante o planejamento e abertura da empresa algumas 
mudanças dentro do curso e dentro da faculdade foram acontecendo, como por exemplo, um ano antes da criação da Empresa júnior, o Curso de Biblioteconomia passou por uma ruptura e, assim, mediante a resolução n‥13/2012 o Curso de Gestão da Informação é integrado a FACOMB.

Apesar dos cursos relacionarem-se entre si, a Gestão da Informação em momento nenhum teve participação na Empresa júnior de Biblioteconomia, como foi feito em outras Empresas júnior de outras universidades. Mesmo assim, a Empresa júnior persistiu realizando poucas atividades até meados de 2016, momento em que o Curso de Gestão da Informação solicitou o espaço da Empresa para a realização de aulas, visto a falta de espaço físico para os cursos desenvolverem suas atividades acadêmicas.

E diante da falta de espaço, a baixa procura dos alunos em participarem da empresa, a dificuldade no processo burocrático documental para a legalização da empresa e a falta de bolsas para os alunos que participavam e se interessavam pela empresa, relata-se que a Empresa júnior do Curso de Biblioteconomia teve suas atividades encerradas em meados do primeiro semestre de 2016.

\subsection{Análise acerca da percepção dos alunos quanto a empresa júnior do curso de Biblioteconomia da Universidade Federal de Goiás}

Diante de tais informações coletadas, houve a necessidade de verificar, mediante os alunos ativos no Curso de Biblioteconomia da UFG, o nível de informação que eles possuem acerca da existência e funcionalidade da Empresa júnior, o grau de interesse dos mesmos em participarem do projeto, bem como verificar se eles consideram que a empresa possibilita algum tipo de contribuição para a formação do perfil consultor dos alunos.

Nessa perspectiva, os alunos entrevistados foram informados que a consultoria é uma atividade que objetiva responder ou atender às necessidades do solicitante por meio de aconselhamento ou proposição. E mediante esta informação, foi perguntado (Gráfico 1) se os mesmos sabiam que o bibliotecário pode atuar com consultoria, sendo que 59\% dos entrevistados disseram que sabiam de tal informação e $41 \%$ informaram que não sabiam.

A diferença entre os resultados representa que há a necessidade de uma maior orientação dos alunos do Curso de Biblioteconomia acerca da atuação do profissional como consultor, de forma a amplificar na mente dos alunos o campo de atuação que ele pode trabalhar, bem como fornecer informações que contribuam com o entendimento do que vem a ser a consultoria na área da Biblioteconomia e despertar nos alunos a visão empreendedora.

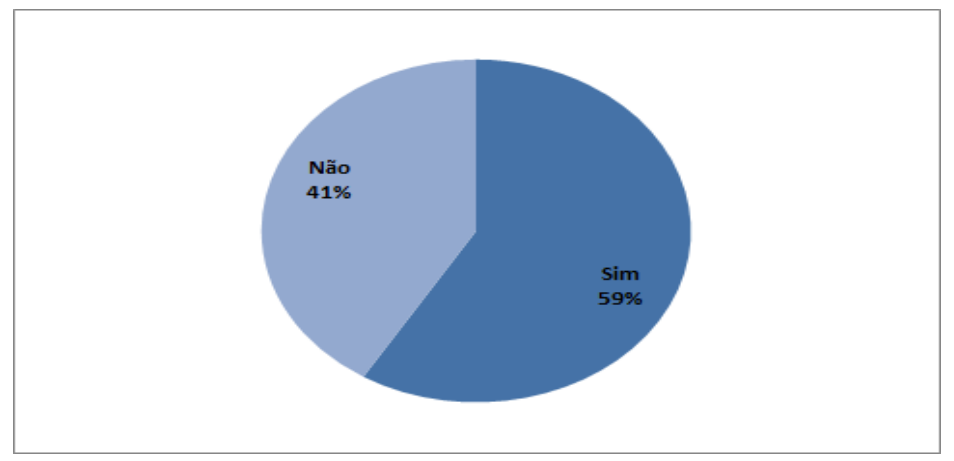

Gráfico 1: Você sabia que o bibliotecário pode atuar com consultoria? Fonte: Elaborado pelos autores. 
Quando perguntado aos alunos se eles tinham interesse em trabalhar com consultoria (Gráfico 2), observa-se que 61,8\% afirmaram ter interesse e 38,2\% disseram que não tinham interesse.

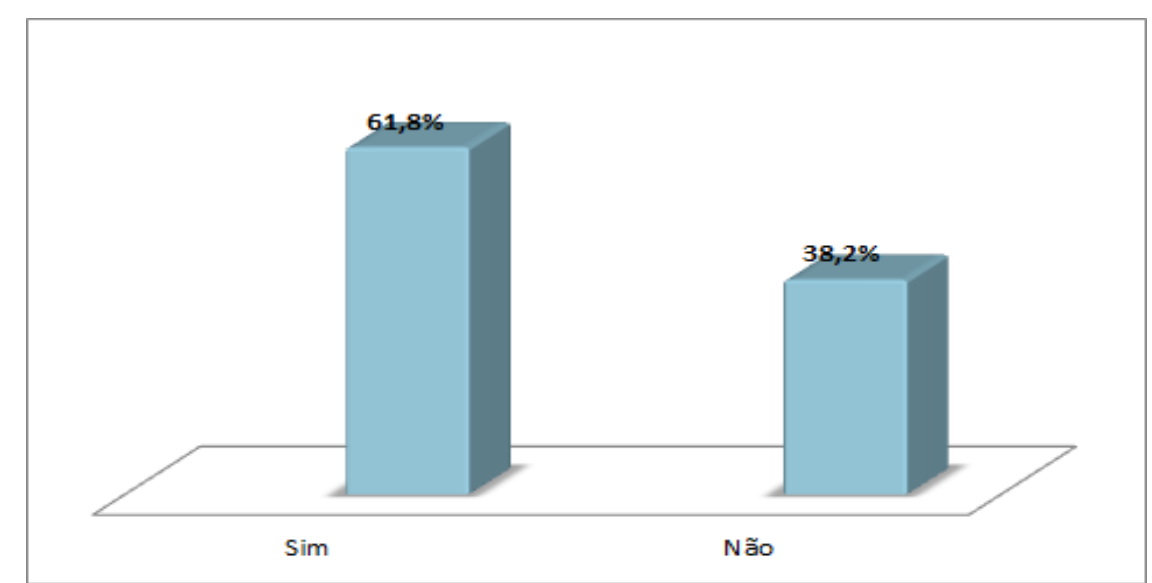

Gráfico 2: Você tem interesse em trabalhar com consultoria?

Fonte: Elaborado pelos autores.

A partir dos dados coletados pôde-se inferir que a maior parte dos alunos entrevistados possuem um perfil empreendedor e que os mesmos já despertaram para a necessidade de um mercado de trabalho mais amplo, do qual o bibliotecário está inserido. No entanto, é pertinente destacar que os respondentes que afirmaram não ter interesse em atuar como consultores podem ser aqueles que almejam atuarem apenas em bibliotecas ou até mesmo na docência e que talvez não tenham o entendimento mais aprofundado acerca de como ocorre a atuação do bibliotecário como consultor, de modo a não despertar interesse nesse campo. Sendo assim, destaca-se a necessidade de inserção de disciplinas de empreendedorismo na grade curricular do Curso de Biblioteconomia, de modo a favorecer o entendimento dos alunos acerca da Empresa júnior e da atuação dos mesmos no campo de consultoria.

Nessa vertente, os respondentes foram questionados se a Empresa júnior pode ajudar na formação de futuros consultores (Gráfico 3) e 91,2\% afirmaram que sim e apenas 8,8\% disseram que não.

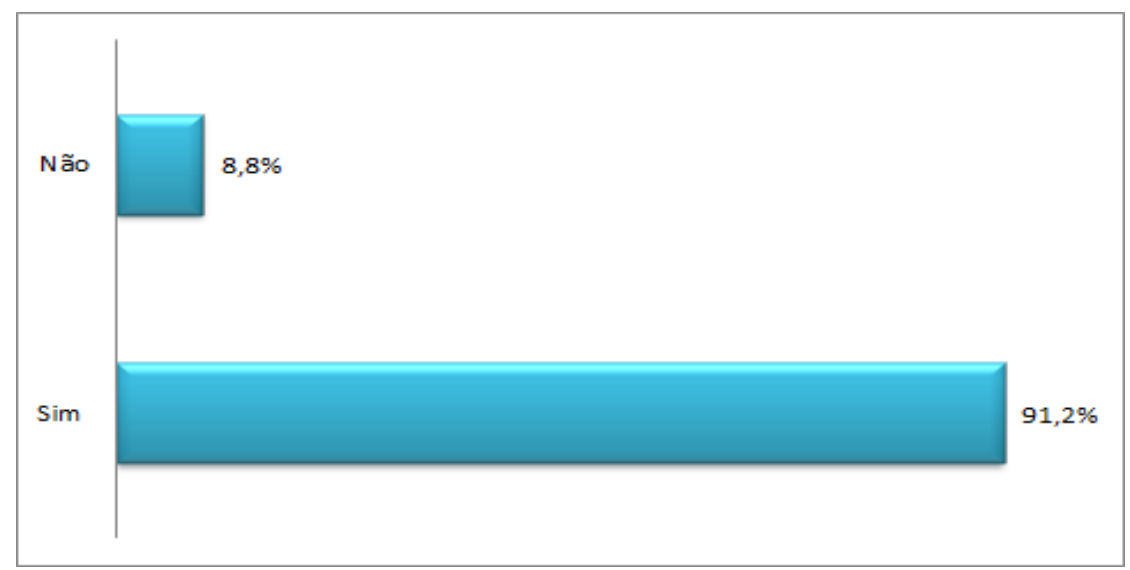

Gráfico 3: A Empresa júnior pode ajudar na formação de futuros consultores?

Fonte: Elaborado pelos autores. 
Nessa perspectiva, pôde-se depreender que uma quantidade significativa de alunos do Curso de Biblioteconomia da UFG possui a correta noção da funcionalidade de uma Empresa júnior dentro de uma universidade. Este resultado quando comparado ao gráfico 2 nos faz refletir que os estudantes respondentes possuem a noção da importância da Empresa júnior, mas que, porém, esta não possui uma forte aceitação de atuação por metade dos respondentes. Isto, talvez, deve-se ao fato de que a Empresa júnior do Curso de Biblioteconomia não ter tido um longo período de atuação, transmitiu aos alunos a falta de confiança neste mercado de trabalho.

A partir da observação anterior, verifica-se por meio do Gráfico 4 que 52,9\% dos alunos respondentes já ouviram falar ou conheceram a Empresa júnior do Curso de Biblioteconomia.

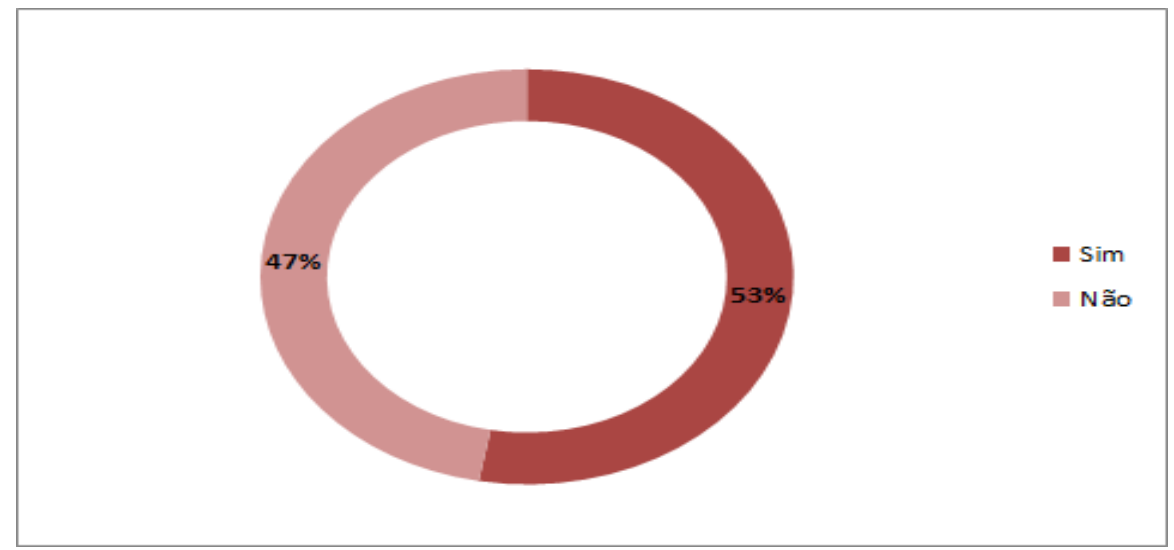

Gráfico 4: Você já ouviu ou conheceu a Empresa júnior da Biblioteconomia?

Fonte: Elaborado pelos autores.

A partir dos dados do gráfico acima se faz uma análise de que a Empresa júnior não se tornou conhecida por todos os alunos do curso, visto que a mesma teve uma duração de 3 anos, de 2013 a 2016, e os respondentes são alunos que ingressaram na universidade de 2012 até 2017, período em que a Empresa júnior teve boa parte de sua atuação.

Sendo assim, percebe-se que houve uma falha no processo comunicacional entre a Empresa júnior, a coordenação do Curso e os alunos de Biblioteconomia, visto que há um alto percentual de alunos que desconhecem a Empresa e tal fato pode ter ocasionado a não participação desses alunos nas atividades desempenhadas pela mesma.

Nessa vertente, verifica-se que durante o período de execução da Empresa júnior deveria ter sido ofertados mais workshops, minicursos e palestras sobre empreendedorismo para os alunos e os professores, para favorecer a compreensão da importância da Empresa para o corpo discente e docente da instituição.

Tal fato mostra-se importante, quando se analisa o gráfico 5 , que informa que $79,4 \%$ dos alunos responderam que nunca buscaram informações sobre a Empresa júnior dentro da UFG. 


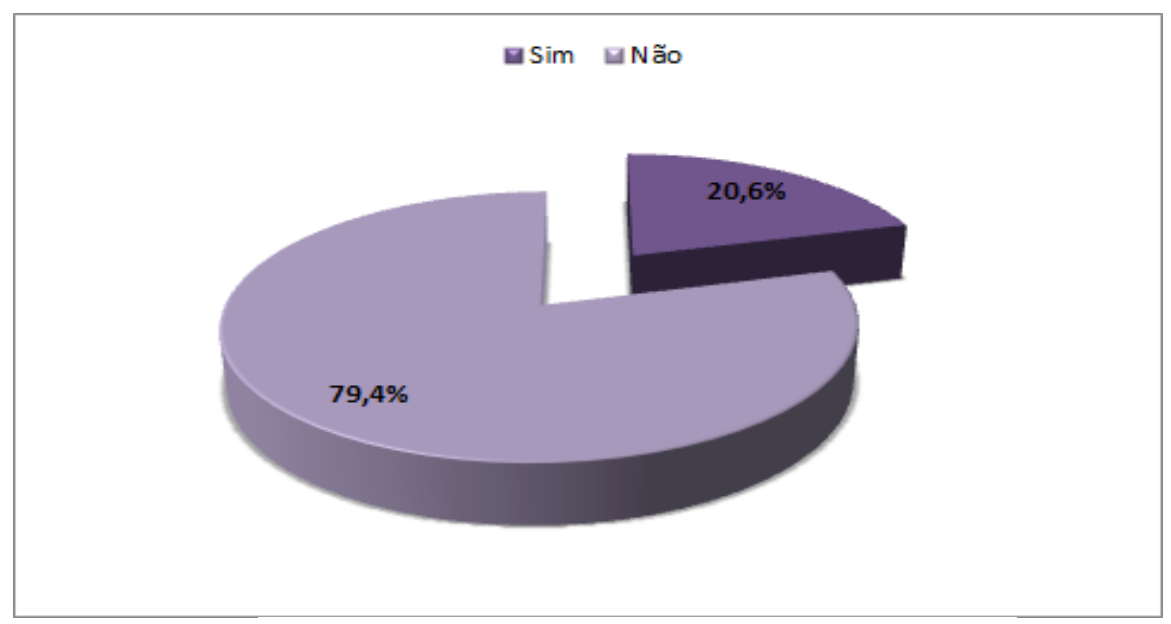

Gráfico 5: Você já buscou informações sobre a Empresa júnior dentro da UFG?

Fonte: Elaborado pelos autores.

Por meio desses dados depreende-se que boa parte dos alunos não buscam informações sobre a Empresa júnior, por desconhecerem ou não terem interesse sobre o assunto, visto que a partir das análises aqui realizadas, observa-se que muitos alunos não se sentiram envolvidos com a Empresa que funcionava no Curso, mediante a falta de informações sobre a mesma.

Tais afirmações podem ser confirmadas meio do gráfico 6 abaixo, no qual ressalta que $100 \%$ dos alunos respondentes acham que a Empresa júnior e suas funções (que hoje não estão em funcionamento) não foram divulgadas adequadamente aos alunos.

Nessa perspectiva, depreende-se que para a aceitação e bom funcionamento de uma Empresa júnior no âmbito universitário, se faz imprescindível a participação de todo o corpo docente e conhecimento de todo o corpo discente acerca da funcionalidade e objetivos da Empresa júnior, como forma de despertar nos alunos a visão empreendedora que o bibliotecário necessita em sua formação e que pode ter acesso a esta por meio de conhecimentos práticos, além da sala aula, como é o caso das Empresas Juniores.

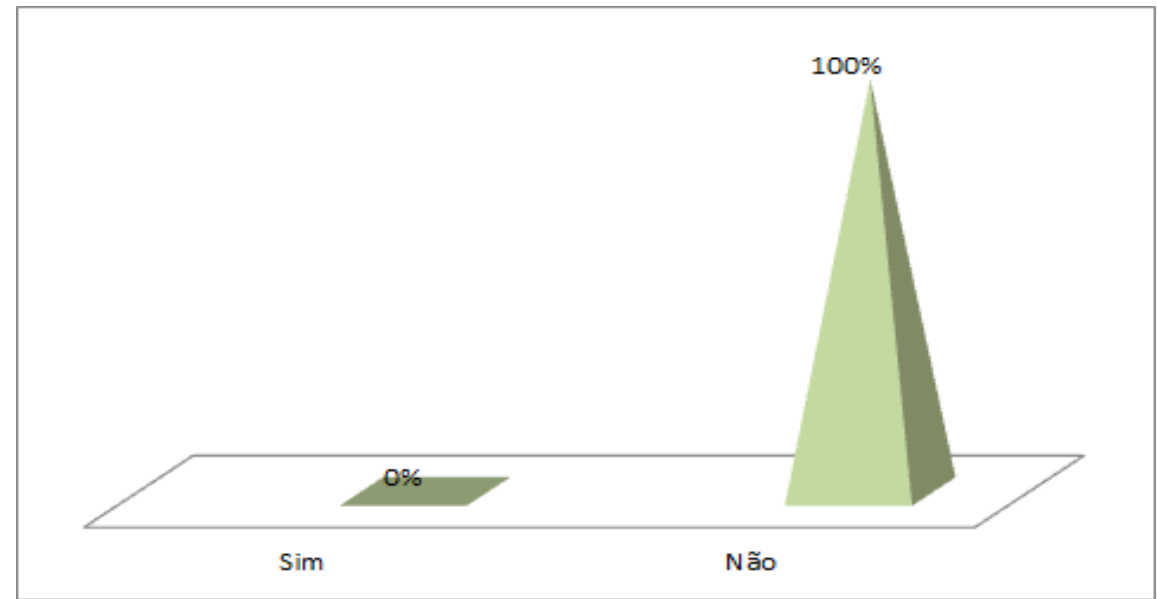

Gráfico 6: Você acha que a Empresa júnior foi divulgada adequadamente?

Fonte: Elaborado pelos autores.

Verifica-se que a Empresa júnior de Biblioteconomia da UFG não teve a 
participação de um número relevante de alunos, pois quando questionados se em algum momento da graduação em biblioteconomia eles participaram do projeto de implantação ou manutenção das atividades da Empresa júnior (Gráfico 7), apenas 5,9\% afirmaram ter participado, enquanto $94,1 \%$ disseram que não interagiram ou atuaram.

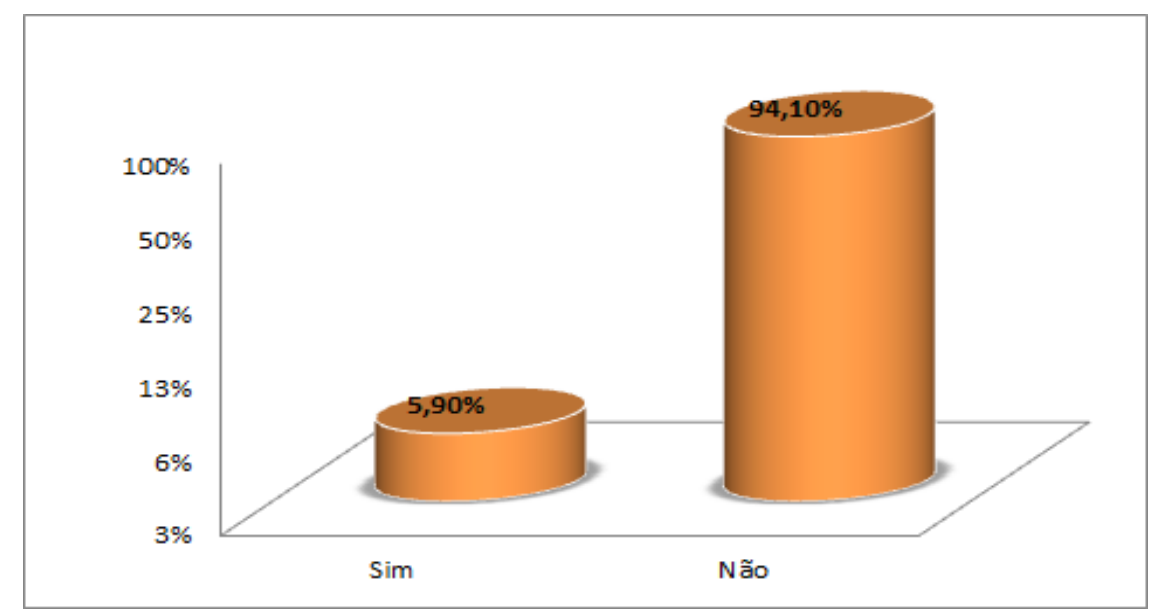

Gráfico 7: Você participou do projeto de implantação ou manutenção das atividades da Empresa júnior?

Fonte: Elaborado pelos autores.

Em contrapartida, quando questionados se eles já tiveram ou têm interesse em participar da Empresa júnior do Curso de Biblioteconomia (Gráfico 8), 76\% responderam que sim e apenas $24 \%$ disseram que não.

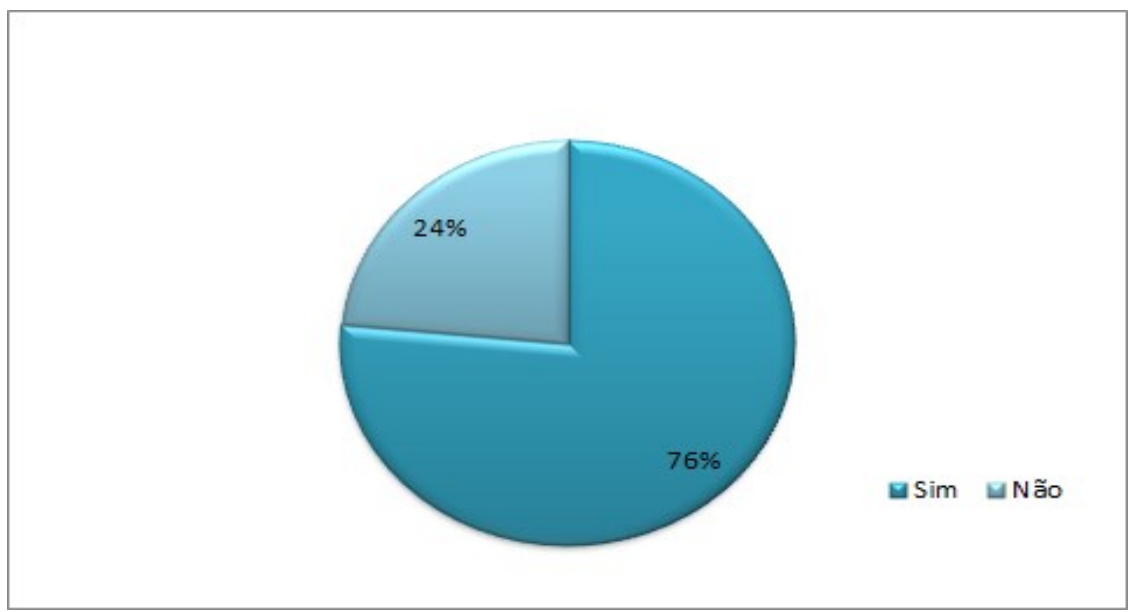

Gráfico 8: Você já teve ou tem interesse em participar da Empresa júnior?

Fonte: Elaborado pelos autores.

Sendo assim, ao se fazer uma análise entre os gráfico 2, 3 e 8 que ressaltam que a maioria dos alunos: tem interesse em trabalhar em consultoria; afirmam que a Empresa júnior pode ajudar na formação dos consultores; e que possuem o interesse em participar da Empresa, pode-se asseverar que apesar do projeto não ter tido um tempo longo de atuação, os alunos se interessam por consultoria e talvez pela falta de informações sobre o que vem a ser uma Empresa júnior e como o Bibliotecário pode atuar no campo da consultoria, verifica-se que os alunos não participaram ativamente do processo de implantação e funcionalidade da Empresa. 
Buscando compreender de forma mais detalhada os fatores que incentivam e impedem a participação dos discentes do Curso de Biblioteconomia na Empresa júnior, apresenta-se os gráficos 9 e 10 que mostram as opiniões dos respondentes.

No gráfico 9 foi questionado acerca dos motivos que levariam a participação dos alunos na Empresa júnior do Curso e dentre as 5 opções apresentadas, destaca-se com $42,5 \%$ de respostas o fato dos mesmos buscarem adquirir experiência para o mercado de trabalho, sendo relevante destacar que nesta questão os alunos poderiam marcar mais de uma opção.

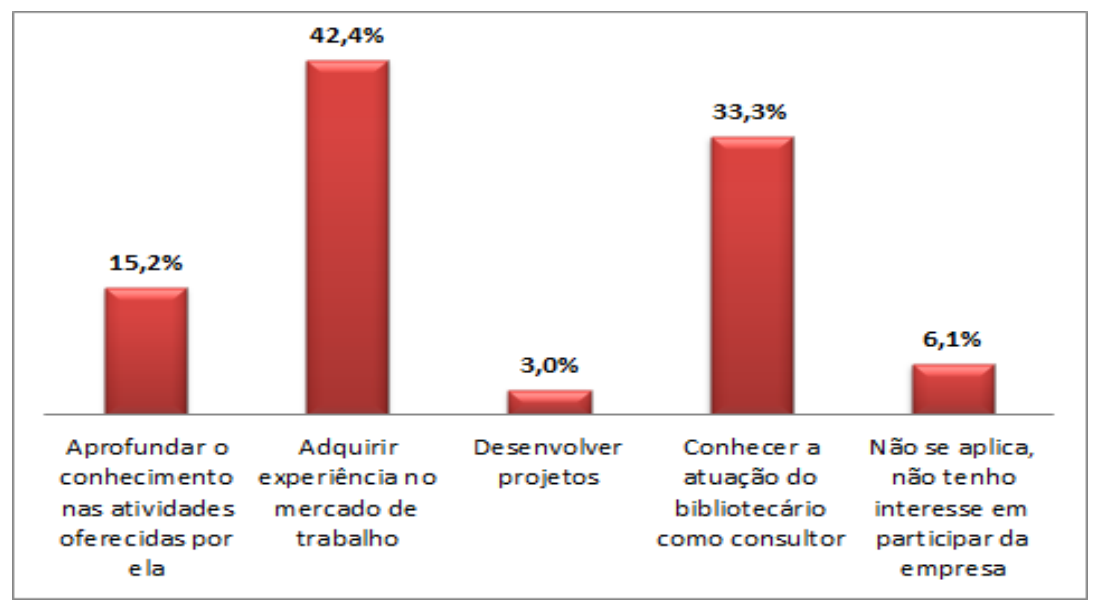

Gráfico 9: Qual motivo te levaria a participação da Empresa júnior da Biblioteconomia? Fonte: Elaborado pelos autores.

Em segundo lugar, com 33,3\% das respostas, apresenta-se a justificativa de querer conhecer a atuação do bibliotecário como consultor, em terceiro lugar com $15,2 \%$, os alunos responderam que têm interesse em aprofundar o conhecimento nas atividades oferecidas pela Empresa júnior, na quarta opção, 6,1\% dos alunos responderam não ter interesse em participar da Empresa e 3,0\% afirmaram que querem desenvolver projetos na Empresa.

De modo geral, verifica-se a alta aceitação dos alunos e o interesse em se prepararem para o mercado de trabalho, ao terem o entendimento de que o processo de consultoria pode ser mais um âmbito de atuação profissional após o seu egresso da faculdade.

Quanto aos motivos que impedem os alunos a participarem da Empresa júnior (Gráfico 10), os alunos podiam marcar mais de uma opção e destaca-se com $50 \%$ a resposta de falta de tempo para se dedicar a Empresa, visto que a mesma não possuía bolsas e caso a Empresa voltasse a funcionar, este fato dificultaria a participação dos discentes que necessitam de uma renda financeira para se deslocarem até o local.

Em seguida, com 47,1\% os respondentes afirmam que não participam da Empresa júnior por não terem informações que possibilitem uma maior compreensão do que vem a ser a Empresa, como funciona e quais os objetivos da mesma. 


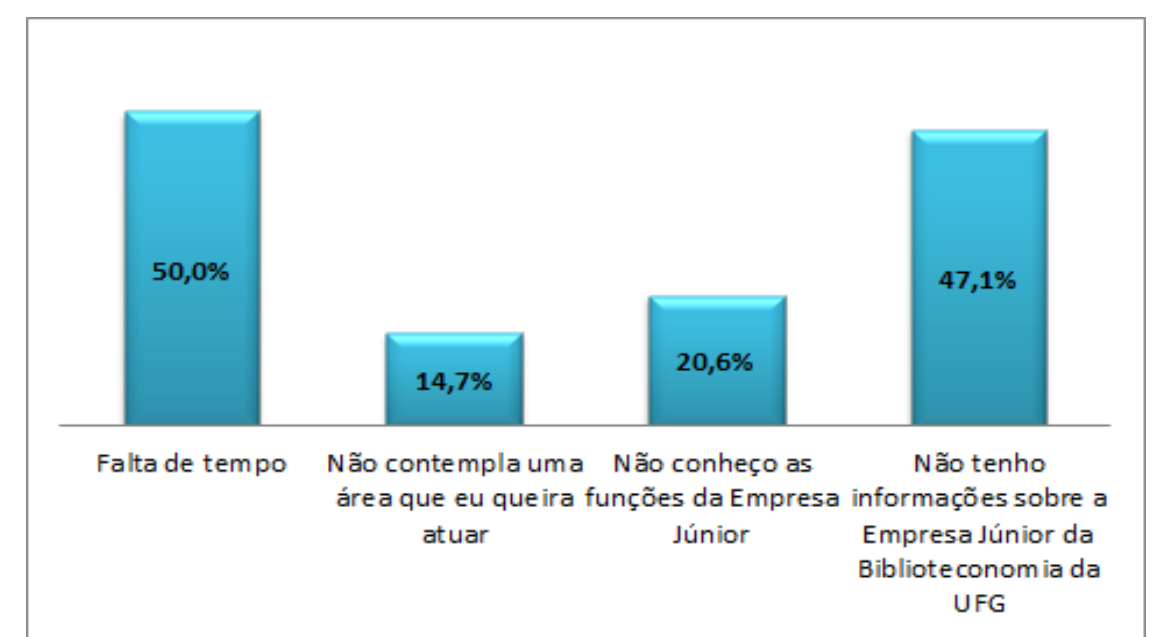

Gráfico 10: Quais motivos não te levariam a participar da Empresa júnior.

Fonte: Elaborado pelos autores.

Já com 20,6\% de respostas, os alunos disseram que o fato de não saberem as funções da Empresa fazem com os mesmos não queiram atuar nesta área. E 14,7\% dos discentes afirmaram que a Empresa não contempla uma área que eles têm interesse em atuar como profissionais.

No geral, observa-se que os dados coletados nesta pesquisa foram muito importantes para validar as análises dos gráficos, pois complementam o entendimento da aceitação da Empresa júnior pelos discentes, assim como possibilita identificar que os alunos do Curso de Biblioteconomia da Universidade Federal de Goiás (UFG) possuem um perfil consultor, porém não é proporcionado pelos recursos oferecidos através da Empresa júnior do Curso de Biblioteconomia.

\section{CONSIDERAÇÕES FINAIS}

Considerando os dados levantados foi possível delimitar fatos que contam uma parte da história da Empresa júnior de Biblioteconomia da UFG, bem como é possível verificar que o objetivo proposto neste estudo foi alcançado, pois foi possível identificar que a maioria dos alunos do Curso de Biblioteconomia da UFG se interessa pela atuação na área de consultoria, porém a Empresa júnior que existe no curso não está em pleno desenvolvimento de suas atividades, o que impede que explorem mais essa vertente profissional. Identificou-se também que os alunos sabem da existência da Empresa júnior, porém não se interessam em buscar quaisquer informações sobre a mesma e sabem que o profissional pode atuar nessa área; a maioria não participa e nem participou da criação ou manutenção da Empresa quando em funcionamento; constatou-se que maior parte dos alunos que responderam o questionário sabem que a Empresa júnior pode ajudar na formação do perfil consultor e também pôde-se verificar que os alunos pretendem trabalhar com consultoria em uma possibilidade futura.

Conclui-se que a Empresa júnior do Curso de Biblioteconomia da UFG não contribui para a formação do perfil consultor dos graduandos, visto que ela não está em pleno funcionamento e não existem planos de uma reformulação da mesma. Para mudar essa situação, propõe-se que seja elaborado um plano de marketing e divulgação explicativa da Empresa e suas funções e, além disso, que seja formada uma comissão para dirigir e manter a Empresa em pleno funcionamento. 
Assim, se faz necessário um empenho maior tanto na divulgação, quanto no projeto para que os alunos possam contribuir para a Empresa júnior deste curso dentro da universidade, já que é de suma importância para a formação esse tipo de contato dentro da graduação, já que insere os alunos no mercado de trabalho e amplia seus conhecimentos.

Sugere-se iniciar uma nova abertura de EJ juntamente com o Curso de Gestão da Informação, único outro curso da área de informação da FIC. A exemplo de outras Empresas em que essa união deu certo, espera-se que além de melhorar a relação entre os cursos, que também haja um maior conhecimento sobre as áreas a serem exploradas pelos profissionais dessas áreas. Também se faz necessário avaliar a grade e identificar as matérias que influenciam a visão empreendedora dos profissionais em formação e, posteriormente, se necessário, propor mudanças na grade para que sejam inseridas matérias que estimulem o perfil empreendedor dos estudantes.

Conclui ressaltando a importância de estudar a temática visto a necessidade de evidenciar na área de Biblioteconomia as Empresas juniores como ferramenta de ensino acerca do empreendedorismo despertando os olhares dos discentes para uma área de atuação carente de profissionais no Brasil.

\section{REFERÊNCIAS}

BRASIL. Ministério do Trabalho e Emprego. Classificação Brasileira de Ocupações: profissionais da informação. Brasília, 2002. Disponível em: <http://www.ocupacoes.com.br/cbomte/261205-bibliotecario >. Acesso em: 1 mar. 2017.

BRASIL Junior. Conceito Nacional de Empresa Júnior - CNEJ, 2007. Disponível em: $<$ http://brasiljunior.org.br/uploads/institutional/file/file/5/CNEJ.pdf >. Acesso em 1 de mar. 2017.

CENTRO DE EMPREENDEDORISMO E INCUBAÇÃO, 2017. Disponível em: $<$ https://cei.ufg.br/p/17181-o-centro-de-empreendedorismo-e-incubacao-cei $>$. Acesso em: 14 de nov. 2017.

CGI JÚNIOR. Consultoria para gerência de informações. Minas Gerais: 2010. Disponível em: $<$ http://cgijunior.blogspot.com.br>. Acesso em: 13 de mar. 2017.

GERHARDT, Tatiana Engel; SILVEIRA, Denise Tolfo. Métodos de pesquisa. Porto Alegre: Editora da UFRGS, 2009.

GIL, Antônio Carlos. Como elaborar projetos de pesquisa. 4. ed. São Paulo: Atlas, 2007.

MATOS, Franco de. A empresa júnior no Brasil e no mundo: o conceito, o funcionamento, a história e as tendências do movimento EJ. São Paulo: Martin Claret, 1997.

MILANO, Manoelle. Cristine. Dalri.; DAVOK, Delsi. Fries. Consultor de informação: serviços prestados por empresas de consultoria nas áreas de biblioteconomia e gestão da informação.

Revista ACB, Florianópolis, v. 14, n. 1, p. 253-278, mar. 2009. Disponível em:

<https://revista.acbsc.org.br/racb/article/view/658/726>. Acesso em: 1 mar. 2017.

UnIVERSidAde federal DE GOIÁS. Projeto Político Pedagógico: Curso de Biblioteconomia da Universidade Federal de Goiás. 2016. [Documento não publicado].

PINHEIRO, Ana Cleide Lucio et al. Os diversos espaços de atuação para o profissional 
bibliotecário. Múltiplos Olhares em Ciência da Informação, v.2, n.2, out. 2012. Disponível em: $<$ http://portaldeperiodicos.eci.ufmg.br/index.php/moci/article/viewFile/1698/1148>. Acesso em: 1 mar. 2017.

SOUZA, Thaís Gabrielly Fernandes. 0 Ensino de Biblioteconomia na Universidade Federal de Goiás: uma análise dos currículos do curso 1980-2004. 2017. 76 f. Trabalho de Conclusão de Curso (Graduação), Universidade Federal de Goiás, Faculdade de Informação e Comunicação

(FIC), Biblioteconomia, Goiânia, 2017. Disponível em: <https://goo.gl/mEJ1Ek>. Acesso em: 10 de novembro de 2017.

UNIVERSIDADE FEDERAL DE GOIÁS. Resolução n. 135/1979. Dispõe sobre a criação do Curso de Biblioteconomia na Universidade Federal de Goiás. Goiânia, 1979. Disponível em:

$<$ https://sistemas.ufg.br/consultas publicas/resolucoes/arquivos/Resolucao CEPEC 1979013 5.pdf $>$. Acesso em: 1 de novembro de 2017.

UNIVERSIDADE FEDERAL DE GOIÁS. Resolução - CONSUNI no 13/2012. Transfere a sede do curso de graduação em Gestão da Informação, criado pela Resolução CONSUNI № 16/2008, do Instituto de Informática - INF para a Faculdade de Comunicação e Biblioteconomia - FACOMB da Universidade Federal de Goiás. Disponível em: <https://www.ufg.br/n/63397-resolucoes $>$.

Acesso em: 14 nov. 2017. 